\title{
LEITURA COMPARTILHADA: UMA IMPORTANTE ESTRATÉGIA PARA PROMOVER A EDUCAÇÃO LITERÁRIA NA SALA DE AULA
}

\section{COLLECTIVE READING: AN IMPORTANT STRATEGY TO PROMOTE LITERARY EDUCATION IN THE CLASSROOM}

\author{
https://doi.org/10.20873/uft2179-3948.2020v11n3p148-169 \\ Érick Airton de Freitas Santos ${ }^{1}$ \\ Valdirene Barboza de Araújo Batista ${ }^{2}$
}

\begin{abstract}
Resumo: Muitas pesquisas sobre o ensino da literatura vêm sendo desenvolvidas no Brasil e, não raro, expõem percalços enfrentados pelos educadores para consolidar essa prática em ambiente escolar. Ainda que, atualmente, os professores tenham à disposição uma bibliografia teórico-metodológica que preconiza o ensino da literatura de modo relevante, muitas fragilidades permanecem. Nesses termos, conscientes dos diversos fatores ligados à formação de leitores literários, objetivamos discutir alguns entraves que dificultam a educação literária e, ao mesmo tempo, socializar uma experiência positiva com a leitura compartilhada, uma estratégia metodológica proposta por Isabel Solé (1998) para o ensino da literatura em contexto escolar.
\end{abstract}

Palavras-chave: educação literária; escola; leitura compartilhada; Bisa Bia, Bisa Bel

\begin{abstract}
Many researches on literature teaching developed in Brazil highlight problems encountered by educators to strengthen this practice at school. Although currently teachers do have at their disposal a theoretical-methodological bibliography that adequately promotes literature teaching, many flaws persist. Thus, conscious of the several factors involved in literary readers' construction, this article discusses some of the obstacles that hinder literary education while, at the same time, share a positive experience with collective reading, a methodological strategy proposed by Isabel Solé (1998) for literature teaching at school.
\end{abstract}

Keywords: literary education; school; collective reading; Bisa Bia, Bisa Bel

\section{Introdução}

No contexto do Brasil redemocratizado, o ato de ler, com base, em especial, nas proposições de Paulo Freire (1991), passou a ser concebido como uma forma de compreender

\footnotetext{
${ }^{1}$ Graduando em Letras Português/Inglês pela Universidade Estadual do Norte do Paraná - UENP (Campus de Jacarezinho); Agente Universitário no Centro de Ciências Sociais Aplicadas da mesma universidade. E-mail: eriqxcx@gmail.com

${ }^{2}$ Doutora pela Universidade Estadual Paulista Júlio de Mesquita Filho - UNESP (Campus de Assis); Professora Colaboradora do Centro de Letras, Comunicação e Artes da Universidade Estadual do Norte do Paraná -UENP (Campus de Jacarezinho); Professora Estatutária da Secretaria de Educação do Estado do Paraná. E-mail: valdirenebab@gmail.com
} 
o mundo. Dominar competências e habilidades de leitura se tornou essencial para o homem contemporâneo, uma vez que vivemos numa sociedade letrada e quem não tem acesso a ela fica à margem da sociedade, impedido de exercer plenamente a sua cidadania. É pela leitura que buscamos sentidos para a vida, que interagimos com o outro, que conservamos a memória do passado. É também pela leitura que o leitor se descobre a si e ao outro dentro do tempo e do espaço. A leitura é, em suma, "uma prática frutuosa da qual o sujeito sai transformado." (JOUVE, 2002, p. 38).

Por conta disso, na visão de diversos estudiosos, praticar a leitura em diferentes contextos requer a compreensão das esferas discursivas em que os textos são produzidos e circulam, bem como o reconhecimento dos interlocutores do discurso e de suas intenções. Apesar da devida valorização que hoje se dá aos mais variados gêneros textuais, é inegável que o texto literário tem ganhado lugar de destaque nos estudos que focalizam o processo de formação do leitor. Isso porque, conforme já nos ensinou Antonio Candido (1972), a comunicação literária exerce, no homem e na sociedade, um papel humanizador e transformador. Na perspectiva desse autor, a literatura pode atuar sobre o indivíduo de várias maneiras: mobilizando a imaginação, satisfazendo as necessidades de ficção e fantasia, chamando a atenção para as mazelas da sociedade, enriquecendo a percepção e a visão de mundo, possibilitando a aquisição de conhecimento, e "por isso pode formar/ensinar, com toda a força de sua invenção e todos os riscos e 'perigos' de suas possibilidades de evasão e fantasia." (MORTATTI, 2007, p. 12).

Diferente do que foi no passado, o intuito agora é formar um leitor capaz de sentir e de expressar o que sente, de fruir esteticamente o texto literário, considerando as especificidades da tríade obra/autor/leitor, por meio de uma interação que está presente na prática de leitura. Nesse cenário, a orientação dos documentos oficiais é que o ensino deve estar centralizado na obra literária, sem descartar a importância do contexto histórico-social e cultural em que ela foi produzida e as particularidades de quem a produziu - até porque tudo isso faz parte da própria tessitura da linguagem.

Posto isso, desde que Maria Thereza Fraga Rocco, na década de 1970 (ROCCO, 1981), desenvolveu o primeiro trabalho emblemático sobre o ensino da literatura em terras brasileiras, muitos outros vêm sendo desenvolvidos país afora. Tais estudos, ora evidenciam que algumas atividades desenvolvidas em contexto escolar para promover a educação literária ainda são muito frágeis, pouco contribuindo para a efetivação desse objetivo, ora apontam estratégias 
teórico-metodológicas relevantes, evidenciando que é possível promover ações criativas e eficazes a favor da formação do leitor literário no ambiente escolar.

Com vistas a contribuir com esse debate, o propósito deste texto é discutir a educação literária na educação básica a partir de duas perspectivas: 1) refletir sobre determinados impasses no âmbito do ensino da literatura em contexto escolar, tendo como base alguns dados levantados pela quarta edição da pesquisa Retratos da Leitura no Brasil, realizada em 2015, os quais ajudam a compreender a complexidade da questão, dialogando com discussões já realizadas por especialistas do tema; 2) discutir a importância da leitura feita pelo(a) professor(a) em sala de aula para a formação de leitores de literatura, atividade em que o(a) docente poderá ler com e para os estudantes em um momento de partilha, voltado para a fruição do texto literário, estratégia que coloca o(a) professor(a) como mediador(a) e modelo de leitor(a), assim como propõem Machado (2001a) e Pennac (1995).

Na esfera do segundo objetivo, serão apresentados os resultados da análise de produções de estudantes de uma escola pública da rede estadual de ensino paranaense, localizada em Jacarezinho/PR, no âmbito da leitura compartilhada do livro Bisa Bia Bisa Bel, de Ana Maria Machado, realizada com duas turmas do ensino fundamental, séries finais. A coleta do material se deu em 2019, momento em que os estudantes estavam matriculados no $7^{\circ}$ ano, durante as aulas de Língua Portuguesa. A análise evidenciou que a leitura feita pelo(a) professor(a) pode ser uma importante estratégia metodológica para promover a educação literária no contexto da sala de aula, principalmente, quando os estudantes ainda não estão seduzidos pela leitura.

\section{Um problema secular}

Todo o esforço para construir um país de leitores despendido por vários setores da sociedade brasileira, mesmo que em sobressaltos, tem surtido efeito positivo, haja vista os resultados que vêm sendo obtidos pela Pesquisa Retratos da Leitura no Brasil, realizada pelo Instituto Pró-Livro desde 2001. O último levantamento aponta que o número de leitores em território nacional vem aumentando ano a ano, passando de 50\% da população em 2011 para 56\% em 2015. Fatores sociais, políticos, econômicos, históricos e culturais, entrelaçados, podem ajudar a compreender e explicar a dificuldade que as escolas brasileiras têm encontrado para formar leitores de literatura na educação básica. Tendo em vista que no espaço deste texto não cabe uma análise minuciosa dessas questões, lançaremos luz, por ora, a apenas alguns 
elementos que têm interferido, consideravelmente, na educação literária das crianças, adolescentes e jovens brasileiros, em especial, os da escola pública.

O primeiro ponto a se chamar a atenção é que, mesmo que boa parte dos brasileiros valorize e reconheça os benefícios proporcionados pela leitura, nem todos estão dispostos, ou não estão habilitados, a fazer o esforço que demanda essa prática de linguagem. A quarta edição da Retratos da Leitura no Brasil, por exemplo, sinaliza que as pessoas não têm receios de assumir que não gostam, não têm paciência ou até mesmo que se sentem muito cansadas para realizar uma leitura. Algumas alegam não ter tempo para ler, e há as que preferem realizar outras atividades. Essas respostas predominam entre os não leitores, no entanto, mesmo que em recorrência menor, também aparecem entre os que se declaram leitores quando indagados acerca das razões que os impediram de ter lido mais. Logo, tem-se um dos primeiros desafios a ser colocado para a instituição escolar: promover o gosto pela leitura literária de modo que o indivíduo leia pelo simples prazer de ler.

Esse desafio nos leva a um outro impasse: embora possa ser uma atividade prazerosa, como já enfatizou Isabel Solé (1998), ler não é uma tarefa fácil, pois é preciso dominar as habilidades de decodificação e aprender as distintas estratégias cognitivas que levam à compreensão de um texto. O sujeito precisa ser capaz de participar de um processo constante de emissão e verificação de hipóteses que conduzem à construção de sentidos. Na ótica dessa pesquisadora espanhola, para que uma pessoa se envolva em qualquer atividade de leitura, é necessário que ela sinta que é capaz de ler, de compreender o texto tanto de forma autônoma, como apoiada em leitores mais experientes. Do mesmo modo:

Ler é uma prática que exige ficar só, que pede concentração, não oferece estímulo multimídia, mas, principalmente, pede o domínio da competência leitora e do letramento. Ler não é tarefa fácil para quem ainda não foi "conquistado" e é impraticável para quem não compreende aquilo que lê. (FAILLA, 2016, p. 20)

O problema é que dados de pesquisas nacionais e internacionais denunciam as fragilidades em torno da competência leitora dos estudantes brasileiros, que também foram levantadas na esfera da Retratos da Leitura no Brasil. A análise de Failla (2016) mostra que tem aumentado o número de pessoas que afirmam possuir algum tipo de dificuldade para ler. Entre os entrevistados, somente 33\% alegam não ter dificuldade, os demais, com exceção dos $10 \%$ que não souberam responder, afirmam que possuem algum tipo de obstáculo para realizar essa prática de linguagem. Entre as dificuldades apontadas, estão as que seguem: não têm paciência para ler (24\%); lê muito devagar (20\%); tem problemas de visão, ou outras limitações físicas $(17 \%)$; não tem concentração suficiente para ler (11\%); não compreende a maior parte do que lê $(8 \%)$. 
Assim, a falta de domínio da competência leitora e do letramento literário é, sem dúvida, um dos obstáculos para o sucesso da educação literária na educação básica. Mesmo que as pesquisas revelem melhorias nesse cenário, dados oficiais apresentados pelo Indicador de Alfabetismo Funcional (INAF, 2018) evidenciam que, em território nacional, três em cada dez jovens e adultos de 15 a 64 anos - cerca de 38 milhões de pessoas (29\% dessa população) são considerados analfabetos funcionais.

Diante dessa constatação, é compreensível que um sujeito que não tenha proficiência leitora e nível de letramento literário adequado desista do ato de ler com certa facilidade, principalmente quando são consideradas as singularidades do texto literário. Como defende Antonio Candido (2011), a literatura, produção exclusivamente humana, é um objeto construído, resultado do trabalho artístico com a palavra, em que o escritor, ao extrair dos processos histórico-político-sociais as indagações e representações de seu grupo social, propõe um modelo de coerência pela força da palavra organizada, explorando, em especial, a linguagem em sua modalidade conotativa.

Na harmonia indissolúvel entre conteúdo e forma é que o texto literário atua sobre o leitor, possibilitando-lhe a apreensão de conhecimentos, que pode se dar na forma de aquisições conscientes de noções, emoções, sugestões ou inculcamentos, conforme salienta Candido (1995). Portanto, compreender as especificidades do texto literário não é tarefa fácil. A falta de letramento literário pode, certamente, contribuir para o afastamento dos leitores dos textos que circulam na esfera literária, possibilitando que prefiram gêneros textuais menos complexos. Daí que tem sido um grande desafio para as instituições escolares criar condições para que o estudante, no ato da recepção, consiga fazer uma leitura possível e autorizada, mobilizando os recursos necessários para a construção de sentidos de forma autônoma.

Apesar disso, a Retratos da Leitura no Brasil mostra que os brasileiros estão lendo mais, inclusive os que estão fora da escola. Entretanto, as categorias de livros mais lidos são os religiosos, os de autoajuda e os de natureza utilitária. O número de leitores de literatura ainda é reduzido, o que é muito preocupante. Os dados levantados por essa pesquisa mostram que o número de livros de literatura lidos pelos entrevistados não chegou a um livro lido espontaneamente (0,72 livro lido em média), sendo que 0,31 foi lido por indicação da escola. Tais dados denotam que a escola não está conseguindo desenvolver ações que levem os indivíduos que passam por ela a se constituir leitores literários vida afora. Mais preocupante ainda é a constatação de que, mesmo entre aqueles que estão na escola, a prática da leitura literária também está reduzida, o que pode revelar a ausência desse ensino. Como tornar a 
leitura literária parte da vida do estudante se ele não for exposto à essa prática cotidianamente, de forma a compreender que ler textos literários poderá fazer parte de sua vida, assim como assistir à TV e navegar na internet, sem que uma atividade anule a outra?

Refletir sobre essa indagação pode nos levar a estabelecer ancoragem em outros pontos que, de nosso ponto de vista, dificulta a educação literária em contexto escolar, ou seja, inviabiliza uma formação em que, conforme propõe a BNCC do Ensino Fundamental, séries finais (2016), possibilite o contato com as manifestações artísticas em geral, e, de forma particular e especial, com a arte literária, oferecendo as condições necessárias para que o estudante possa reconhecer, valorizar e fruir essas manifestações, desvendando suas múltiplas camadas de sentido, respondendo às suas demandas e firmando pactos de leitura.

Trata-se da natureza das atividades que os jovens costumam praticar em tempo livre, segundo a Retratos da leitura no Brasil. De acordo com essa pesquisa, a leitura aparece na nona colocação, ficando atrás de atividades como assistir à televisão, navegar na internet, ouvir músicas ou rádio, entre outras atividades que, em terras brasileiras, são exercidas no contexto social independente de ensino sistematizado. A leitura, que também pode ser uma atividade de entretenimento, ao contrário, demanda estratégias metodológicas de ensino. Daí a sua escolarização, o que pode provocar um choque entre a natureza gratuita da literatura e a natureza obrigatória das atividades escolares.

Assim, ainda que não possamos afirmar com algum grau de certeza, é possível supor que se a realidade das famílias brasileiras fosse outra, isto é, se o ato de ler fosse uma atividade habitual no meio familiar, o trabalho da escola, provavelmente seria bem menos árduo, uma vez que, se as crianças chegassem à escola já seduzidas pela leitura, o processo de letramento literário poderia enfrentar menos obstáculos. Nesse contexto, vale a pena destacar que, como demonstra a já mencionada pesquisa realizada pelo Instituto Pró-Livro, a mãe e/ou figura feminina são as maiores influenciadoras do gosto pela leitura. Esses dados sinalizam a importância de incentivo a ações públicas que fomentem a prática de leitura no seio familiar de uma forma mais intensa.

Como já foi mencionado, sendo a escola uma instituição de frequência obrigatória, tudo o que é escolarizado tende a receber essa conotação de obrigatoriedade. Por conta disso, muitos estudantes se sentem desestimulados no processo de aprendizagem da leitura, pois, em geral, assimilam essa prática como algo obrigatório, cansativo e pouco interessante, como bem sinalizam os resultados da pesquisa em pauta. A natureza gratuita da comunicação literária tende a ficar sufocada em um ambiente cuja lógica é a sistematização formal do ensino, 
permeada pela avaliação, sendo esta mensurada a partir de uma nota específica, o que, em si, não encerra nada de errado, posto que faz parte da gênese da instituição escolar. A questão é que, se o(a) docente não estiver preparado para fazer isso de uma forma eficiente, é possível que o estudante fique com uma visão muito limitada acerca do porquê e para quê seja importante o desenvolvimento do gosto pela leitura literária.

Em geral, a sociedade capitalista propicia a formação de um indivíduo cujas ações, na maioria das vezes, estão marcadas pelo pragmatismo, o que possivelmente explique em parte o porquê de os leitores brasileiros tenderem a buscar nos livros uma função mais utilitária. Os dados levantados pela Retratos da Leitura no Brasil evidenciam que, apesar de o ato de ler ser visto como uma atividade prazerosa, logo, fundamentada na gratuidade, para a maioria dos entrevistados a leitura tem uma função predominantemente prática, o que pode estar atrelado ao contexto escolar. Decerto, não se pode negar que a leitura possibilita o desenvolvimento do indivíduo em várias direções: intelectual, linguística, social, cultural, profissional, econômica - prática que, de fato, melhora a vida em vários sentidos. No caso da literatura, conforme lembra Andrade (2009), além de ampliar o conhecimento linguístico e intelectual do leitor, a literatura de boa qualidade pode levá-lo ao conhecimento de si mesmo, do outro e do mundo.

Assim, chega-se a mais um embate na relação entre escola e literatura. No caso da primeira, mesmo que não seja possível medir todo o seu alcance na formação do indivíduo, possui, em geral, uma finalidade essencialmente prática, cuja função, segundo a Lei de Diretrizes e Bases da Educação Nacional / LDBEN (Lei 9394/96), é promover o desenvolvimento pleno do educando, preparando-o para o exercício da cidadania e qualificando-o para o trabalho. Já a segunda, embora também seja uma forma de conhecimento, pende mais para a gratuidade. Todavia, é certo que literatura e escola possuem uma natureza formativa, contudo, a essência dessa formação, em um caso e no outro, é de caráter divergente.

Nesse potencial educativo é que residem, pois, alguns dos equívocos que ainda permanecem no processo de escolarização do texto literário. Nesses termos, em ambiente escolar, todo o processo de ensino/aprendizagem ocorre de forma sistematizada, intencional e norteada por objetivos claros e específicos, o que, como já mencionado, faz parte da natureza da escola, não havendo nada de errado com essa prática. Ao final do desenvolvimento de determinadas sequências didáticas, o estudante é avaliado de modo a verificar em que medida ele se apropriou do que foi lhe dado a conhecer. O docente, por sua vez, também é avaliado, visto que, em geral, boa parte da responsabilidade pela não aprendizagem do aluno tem recaído sobre os ombros do professor. 
Acontece que, conforme já tão bem salientou Antonio Candido, a literatura atua, sim, na formação de uma criança e do adolescente tanto quanto a escola e a família, atingindo as camadas mais profundas da personalidade do ser humano, sem que se possa avaliar a sua abrangência. Contudo, fica evidente que o caráter formador da literatura não é semelhante ao da escola, uma vez que forma assim como a vida: com altos e baixos e entre luzes e sombras. Para relembrar, mais uma vez, a bela reflexão de Candido: a literatura não corrompe nem edifica, "mas, trazendo livremente em si o que chamamos o bem e o que chamamos o mal, humaniza em sentido profundo, porque faz viver." (CANDIDO, 1972, p. 806). Resguardadas as devidas exceções, porém, o ensino da literatura segue sendo tratado como eventualidade, parte de algum projeto passageiro voltado para o ensino da leitura literária quando sobra tempo ou por exigência das Secretarias de Educação, posto que, para muitos docentes, a mobilização da fruição literária ainda não faz parte de seu plano de ensino.

De outro lado, muitas vezes, mesmo que munidas de boa intenção, certas práticas destinadas ao ensino da literatura em contexto escolar acabam escamoteando a função humanizadora da literatura, isto é, não vislumbram no texto literário aquilo que confirma o homem em sua humanidade, por ainda usá-lo como pretexto para ensinar unicamente aspectos gramaticais, questões de vestibular ou determinados valores e atitudes atualmente entendidos como politicamente corretos. Do mesmo modo, com receio de didatizar demasiadamente o texto literário, muitos o levam para a sala de aula, mas não exploram as suas potencialidades. Desse modo, tem-se, de um lado, uma prática pautada na liberdade excessiva, em que não se trabalha as especificidades do texto literário, com enfoque na formação do leitor literário que consegue fruir o texto esteticamente, ao mesmo tempo em que compreende a condição artística desse tipo de leitura e de escrita e, de outro, uma metodologia fundamentada na obrigatoriedade e no pragmatismo. Sem contar, o que é pior, as situações em que há uma ausência absoluta do trabalho com o texto literário em sala de aula.

Um exemplo flagrante desse cenário pode vir do fato de que poucos professores estejam conseguindo influenciar o estudante no momento da escolha de um livro para leitura, segundo dados levantando pela já mencionada Retratos da Leitura no Brasil: 11\% na faixa dos 11 aos 13 anos e 12\% na faixa dos 14 aos 17 anos. "Na mesma linha de pensamento, é preocupante que $37 \%$ dos professores respondam que "gostam pouco" ou "não gostam de ler". (CECCANTINI, 2016, p. 95). Ao analisar dados da Retratos da Leitura no Brasil, Ceccantini chama a atenção para a ausência muito marcante, na lista dos livros lidos pelos estudantes, de inúmeros autores brasileiros e estrangeiros, os quais, nas últimas duas décadas, vêm se 
destacando pela boa qualidade de sua produção literária, tendo, por isso, recebido variados prêmios literários nacionais e internacionais. Sobre essa questão, Zoara Failla pondera:

\begin{abstract}
Não há dúvidas de que a mediação, quando promovida pelo professor, pelo bibliotecário, pela família, por um voluntário ou outro agente leitor é poderosa no despertar do interesse pela leitura. Os dados da pesquisa não questionam essa verdade, mas sim apontam para o número de brasileiros que não tiveram a oportunidade de encontrar alguém - na sua escola, na sua família, e até na biblioteca que algum dia frequentou - que lhe oferecesse um livro; que convidasse para uma roda de leitura; que lesse para ele; que o presenteasse com livros; ou, ainda, que perguntasse o que achou de um livro que indicou para ler. (FAILLA, 2016, p. 24 e 25)
\end{abstract}

$\mathrm{Na}$ esfera dessa mesma discussão, pesquisas desenvolvidas por Saraiva e Mügge chamam a atenção para o tratamento dispensado ao texto literário na organização dos currículos escolares, e também constatam a quase ausência da literatura em sala de aula, bem como diagnosticam a "animosidade que os alunos demonstram em face do texto literário, a que se acresce seu conhecimento superficial sobre a literatura brasileira." (SARAIVA e MÜGGE, 2006. p. 27). Sendo assim, criar condições para que o sujeito estudante tenha acesso a estratégias metodológicas conscientes que possam inseri-lo no universo da prática da leitura é uma função de todos os educadores. Como defende a escritora Ana Maria Machado nos vários ensaios organizados no livro Texturas: sobre leitura e escritos, o professor precisa ser exemplo de leitura para seus alunos, uma vez que é, do ponto de vista da escritora, pelo exemplo e pela curiosidade que o mestre poderá despertar seus alunos para o prazer da leitura. Em suas palavras: "imaginar que quem não lê pode fazer ler é tão absurdo quanto pensar que alguém que não sabe nadar pode se converter em instrutor de natação.” (MACHADO, 2001a, p. 122).

Um caminho para isso, acreditamos, é a prática diária da leitura literária em sala de aula por meio da leitura compartilhada, momento em que os professores e estudantes poderão ler de modo a fruir o texto literário, considerando suas potencialidades significativas e estéticas. Ainda que o pleno sucesso da ação docente esbarre em muitos obstáculos, como os já elencados, que se somam às precárias condições salariais e de trabalho nas quais muitos profissionais da educação se encontram, bem como os problemas relacionados à formação docente, o professor desempenha um papel fundamental dentro do processo de formação leitora de seus alunos. Ausentar-se dessa função seria negar a própria essência do magistério.

\title{
2 Ler com e para os alunos
}

À vista do já discutido até o momento acerca das especificidades e potencialidades da literatura, seria bom que a educação literária, em contexto escolar, percorresse dois caminhos que se encontram: um que objetive mobilizar as competências linguísticas, textuais, discursivas 
e cognitivas necessárias para a promoção do letramento literário e outro que potencialize a fruição do texto literário de forma autônoma e gratuita de modo a despertar o gosto pela leitura fora do ambiente escolar. Nas últimas décadas, diferentes estudiosos da leitura têm discutido variadas propostas metodológicas que intencionam oferecer ferramentas para o ensino da literatura. Maria da Glória Bordini eVera Teixeira Aguiar (1998), William Roberto Cereja (2005) e Rildo Cosson (2006) são exemplos de pesquisadores que conceberam metodologias para o ensino da literatura, as quais tiveram um alcance nacional.

Assim, em tempos atuais, não se pode afirmar que exista carência de propostas metodológicas que visem à promoção da educação literária em contexto escolar, posto que há farta e consistente publicação sobre o assunto. Também não é um equívoco afirmar que tais métodos têm sido disseminados pelas Secretarias de Educação e cursos de pós-graduação espalhados Brasil afora, no âmbito da formação continuada dos professores, bem como na esfera da formação inicial de docentes e pedagogos via disciplinas voltadas para o ensino da leitura e da literatura nos cursos de Letras e Pedagogia. A nossa experiência de sala de aula tem mostrado que a adoção de uma metodologia se faz importante na medida em que serve de orientação e suporte para não deixar o ensino caótico e ineficiente, embora a sua utilização não garanta o sucesso da prática pedagógica. Em conformidade com o que já disseram Vera Teixeira de Aguiar e Maria da Glória Bordini, a aplicação passiva de qualquer método, deixando de considerar "as condições circunstanciais da sala de aula, ou a excessiva preocupação com técnicas desvinculadas dos conteúdos que lhes devem servir de suporte burocratizam o ensino, determinando sua perda de significação ante o alunado.” (BORDINI; AGUIAR, 1993, p. 155). Ademais, para além do método, estão os contextos em que se encontram os sujeitos envolvidos nesse processo: professores e alunos.

Posto isso, a leitura compartilhada, discutida e analisada no espaço deste texto, tem como intuito mobilizar a fruição do prazer estético e a formação do gosto pela leitura de forma gratuita. Apesar disso, considerando a natureza da instituição escolar, é possível que o(a) professor(a) avalie todo esse processo, no entanto, é recomendável que os critérios avaliativos sejam orientados pelos pressupostos teóricos da avaliação formativa predominantemente. Sendo assim, a estratégia metodológica em questão demanda poucos esforços e recursos dos docentes. Em contrapartida, é necessário abandonar o pensamento de que a prática diária da leitura literária em sala de aula possa significar prejuízo ao conteúdo programático. Portanto, a adoção da leitura compartilhada exige do(a) docente certa clareza acerca do porquê e para quê levar o texto literário para a sala de aula. 
No Estado de São Paulo, essa metodologia foi bastante disseminada em projetos implementados pela Secretaria de Educação para o ensino da leitura nas escolas estaduais, funcionando, também, como cursos de formação continuada para os professores dessa rede de ensino. São exemplos desses projetos o Tecendo Leituras, desenvolvido em 2004 e 2005, e o Hora da leitura, implantado entre 2005 e 2007. Ainda que cada um deles possua as suas particularidades, ambos lançaram mão da leitura compartilhada como procedimento metodológico na esfera do ensino dessa prática de linguagem. Em geral, fundamentados em estudos sobre as estratégias de leitura, realizados por Isabel Solé (1998), e nas modalidades organizativas de conteúdos escolares, apresentadas por Delia Lerner (2002), tais projetos justificam a escolha da leitura compartilhada em razão dessa metodologia possibilitar que o professor assuma o papel de mediador do processo de aprendizagem da leitura, lendo com e para os estudantes. Na qualidade de leitor experiente, o(a) docente pode ajudar seus discentes - leitores inexperientes - a construir sentidos para o texto, além de levá-los a tornarem-se leitores autônomos.

No caso do Tecendo Leituras, a partir dos estudos das duas estudiosas já mencionadas, a proposta é que os professores compartilhem objetivos de leitura, com base em três modalidades organizativas de conteúdo: atividade permanente; sequência didática, com ênfase em três grandes domínios: ler nas linhas, ler entre as linhas e ler por trás das linhas; e projetos de trabalho. Por sua vez, o Hora da leitura, de caráter interdisciplinar, haja vista a abertura a profissionais de outras áreas específicas para lecionar nas classes em que ele fora implementado, também tinha como proposta o desenvolvimento de um trabalho diferenciado, centrado na leitura compartilhada. A partir dos livros disponíveis nas escolas, os docentes deveriam ler com e para os estudantes, levando-os a interpretar oralmente, a dramatizar textos, a preparar saraus literários, a discutir filmes, a cantar e a interpretar músicas do repertório popular nacional, além de outras atividades que permitissem explorar os jogos de linguagem.

Nesses termos, a leitura compartilhada se coloca como uma estratégia metodológica que enfatiza o papel mediador do professor como leitor experiente e fruidor do prazer estético, fundamental para a efetivação do processo de leitura de seus discentes. No entanto, nessa proposta de trabalho, a tarefa de ensinar e aprender a ler dá-se pela divisão de responsabilidades, entre professores e estudantes, compartilhando objetivos, tarefas e significados, conforme assinala Solé (1998). Na perspectiva dessa pesquisadora, mesmo que a leitura seja um processo interno, essa prática precisa ser ensinada, e uma importante condição para que isso ocorra é o(a) estudante ver e entender como o(a) professor(a) faz para elaborar uma interpretação. Os 
estudantes precisam assistir a um processo de leitura que lhes possibilite ver estratégias de compreensão do texto em ação em uma situação significativa e funcional.

Ademais, conforme já enfatizou Daniel Pennac (1995), para disseminar o gosto e o prazer pela leitura, não se trata de exigi-la, mas de partilhar a felicidade de ler. Professores e estudantes devem juntos vivenciar a experiência da partilha da leitura e, sendo os docentes os mediadores nesse processo, devem ser os primeiros a sentirem a felicidade de ler e aí, certamente, terão sensibilidade para buscar caminhos metodológicos para cultivar, ainda que sem garantia de sucesso, o mesmo desejo nos estudantes, conduzindo-os rumo à intimidade com o texto literário. Neste sentido, Pennac afirma:

Se ele [professor] lê verdadeiramente, põe nisso todo o seu saber, dominando seu prazer, se sua leitura é um ato de simpatia pelo auditório como pelo texto e seu autor, se consegue fazer entender a necessidade de escrever, acordando nossas mais obscuras necessidades de compreender, então os livros se abrem para ele e a multidão daqueles que se acreditavam excluídos da leitura vai se precipitar atrás dele. (PENNAC, 1995, p. 166)

Posto isso, no tópico que segue, apresentamos uma de nossas experiências com a leitura compartilhada do livro Bisa Bia Bisa Bel, de Ana Maria Machado (2001), junto a duas turmas das séries finais do Ensino Fundamental de uma escola da rede estadual de ensino, localizada na cidade de Jacarezinho/PR. Como já informado, as atividades foram desenvolvidas em 2019, momento em que os estudantes cursavam o $7^{\circ}$ ano.

\section{Leitura compartilhada do livro Bisa Bia, Bisa Bel}

De autoria de Ana Maria Machado, Bisa Bia, Bisa Bel é um livro bastante aclamado pela crítica especializada em literatura infantil e pelo público, sendo considerado um dos grandes clássicos do gênero no Brasil. Premiada tanto no Brasil quanto no exterior, a autora ganhou os prêmios Hans Christian Andersen (2000) e Jabuti (1997) e é a atual ocupante da cadeira número um da Academia Brasileira de Letras.

Sumariamente, a narrativa, como afirma a própria escritora, nasce da saudade que a autora sentia de suas avós e da vontade de falar sobre elas com seus filhos, daí surgindo a intenção de estabelecer um diálogo envolvendo três gerações. Nas malhas do texto, Machado materializa essa trança de gente. Na história, Isabel, uma menina pré-adolescente, ganha voz e conta aos leitores suas aventuras e sua ligação com sua bisavó, Bia, e sua futura bisneta, Beta, encontro de gerações que permite diálogos muito pertinentes sobre família, personalidade, amizade e sobre a figura feminina. Nessa primorosa obra, repleta de fantasia, o leitor é levado para dentro da história de tal modo que: "Ficamos íntimos das personagens. Temos a impressão 
de que o que acontece nas páginas do livro acontece na nossa vida. Torcemos, choramos, ficamos tristes quando acontecem coisas ruins, ficamos contentes e felizes quando acontecem coisas boas..." (LAJOLO, 2001, p. 4).

Tomando como base os modelos teóricos propostos por Regina Zilbermann, em $A$ Literatura Infantil na Escola (2003), podemos considerar Bisa Bia, Bisa Bel como uma obra emancipatória, visto que a criança recebe voz na narrativa, cuja história é contada de seu ponto de vista, e o aprendizado é alcançado por meio de suas experiências, estimulando, assim, a criatividade e o pensamento crítico no leitor. A intenção da autora está livre da tentativa de ensinar o que quer que seja aos leitores e, nesse sentido, tudo o que é construído de mais belo durante a leitura é fruto de uma troca entre a tríade escritora/obra/leitor - e é sobre isso que trata a arte da literatura. A primeira publicação de Bisa Bia, Bisa Bel se deu em 1981 pela Editora Moderna, tendo sido distribuídos nas escolas diversos exemplares por meio do programa Literatura em Minha Casa, o que possibilitou que os estudantes do $7^{\circ}$ ano da escola em que ocorreu a pesquisa tivessem a oportunidade de ler o livro individualmente, posto estar disponibilizados na biblioteca muitos exemplares. Nesses termos, importa comentar que esse tipo de programa governamental é fundamental na esfera da democratização do livro e da leitura.

Inicialmente, foi solicitado que todos os estudantes lessem o livro dentro de um prazo de três semanas que, ao que parece, não foi suficiente, uma vez que pouquíssimos realizaram a atividade. De um total de 53 estudantes, somando as duas turmas, apenas 10 leram o livro completo, fato que se evidenciou no dia estabelecido para se ter uma roda de conversa sobre as impressões de leitura da obra, atividade realizada nas duas turmas separadamente.

Como poucos estudantes leram a narrativa, a qual se constitui de apenas 62 páginas, optamos por fazer a leitura compartilhada da obra, sobretudo por acreditarmos que valeria a pena o contato dos estudantes com o texto. Não somente a professora fez a leitura em voz alta como também alguns discentes manifestaram o desejo de fazê-lo, o que foi aceito, embora um grupo tenha se manifestado contrário, alegando que nem todos os colegas liam com expressividade. Isso ocorreu nas duas turmas. Durante a leitura compartilhada, os estudantes levantaram, confirmaram e/ou refutaram hipóteses acerca da trama e de outros aspectos linguísticos e textuais da narrativa. Após a leitura, foi feita uma nova roda de conversa sobre a recepção da obra, momento em que trouxeram à tona, em especial, as temáticas perceptíveis na narrativa, entre elas: namoros e brincadeiras infantis, o papel social da mulher em diferentes gerações, amizades e machismo. 
Importante informar que na ocasião foi feita uma parceria com as estagiárias do Projeto de Extensão Identidades Visuais, desenvolvido sob a coordenação da professora Luciana Brito, da Universidade Estadual do Norte do Paraná, com apoio do Programa Universidade Sem Fronteiras. Sob a orientação da artista plástica Monique Brandão, os estudantes do sétimo ano, em grupos, realizaram uma oficina de pintura, cujos desenhos dialogaram com as temáticas desenvolvidas em cada um dos capítulos de Bisa Bia, Bisa Bel. Assim, além de experimentar momentos de fruição do texto literário, também tiveram contato com uma artista plástica, atividade transdisciplinar que foi bastante significativa para os estudantes. A oficina foi desenvolvida com as duas turmas juntas.

Na esfera dessa leitura compartilhada, os estudantes fizeram duas produções textuais. A primeira foi solicitada quando se encerrou o prazo de três semanas dado às duas turmas para fazer a leitura individual de Bisa Bia, Bisa Bel. Nesse primeiro texto, aqueles que leram registraram suas impressões de leitura da narrativa; já os que não leram informaram as razões que os impediram de consumar a atividade. No segundo texto, tendo em vista que os discentes estavam estudando os elementos composicionais do gênero memórias literárias, solicitamos que escrevessem suas memórias de leitura do livro em questão e, por não ter sido fornecido roteiro prévio, ficaram livres para registrar o que para eles de mais significativo houvera durante o trabalho com a leitura.

Ao todo, foram analisados 68 textos, incluindo 35 impressões de leitura individual, produzidas antes da leitura compartilhada, e 33 memórias de leitura, feitas após a leitura compartilhada. Somando as duas turmas, 43 estudantes produziram os textos, ficando 10 alunos de fora por motivos variados. Ainda que as produções não tenham seguido um roteiro prévio, foi possível levantar algumas recorrências nos textos, como podemos observar no quadro que segue:

\begin{tabular}{|l|c|}
\hline Algumas informações levantadas nas produções & $\begin{array}{c}\text { Número de } \\
\text { estudantes }\end{array}$ \\
\hline Leu o livro inteiro & $\mathbf{1 0}$ \\
\hline Leu o livro em partes & 15 \\
\hline Não leu o livro & $\mathbf{1 8}$ \\
\hline Já havia lido o livro & 5 \\
\hline Gostou/entendeu a história após ler sozinho(a) & 14 \\
\hline Não gostou / não entendeu a história após ler sozinho(a) & 10 \\
\hline
\end{tabular}




\begin{tabular}{|l|c|}
\hline Gostou/entendeu a história após a leitura compartilhada & $\mathbf{2 7}$ \\
\hline Não gostou / não entendeu a história após a leitura compartilhada & 10 \\
\hline Elogiou a leitura compartilhada & $\mathbf{2 0}$ \\
\hline Não gostou da leitura compartilhada & 1 \\
\hline Não prestou atenção na leitura compartilhada & 4 \\
\hline
\end{tabular}

Em geral, nessas produções, ficaram explícitas as carências dos estudantes em relação ao contato com a leitura literária e o papel de leitor ativo que passaram a assumir durante a leitura feita com a professora, compartilhando suas experiências, inferindo sobre a história e fazendo perguntas, debatidas e respondidas pela docente e pelos próprios colegas. Desse modo, o aprendizado se tornou mútuo e recíproco entre professora e estudantes. Ainda que um estudante tenha afirmado não ter gostado da leitura compartilhada e quatro não tenham prestado atenção à atividade, o quadro evidencia que essa ação foi bem-sucedida, já que dos 43 que escreveram os textos, 27 passaram a gostar e/ou entenderam a história a partir da leitura compartilhada, manifestando esse ponto de vista de forma espontânea, uma vez que não tinha sido proposto roteiro prévio para a escrita das memórias de leitura da narrativa Bisa Bia Bisa Bel.

Dessa forma, a leitura compartilhada se revelou uma estratégia importante para aproximar os leitores em formação dos textos literários, via mediação da professora. Em geral, os estudantes que não fizeram a leitura individual da narrativa alegaram ter gostado de conhecer a obra por intermédio da atividade e, sobre isso, um estudante escreve: "[...] o que eu mais gostei foi a leitura compartilhada porque daí é mais fácil a professora ler para eu e as demais entenderem [...] para mim comentar sobre a história foi muito legal para saber mais a opinião das pessoas". ${ }^{3}$ Nessa declaração, é possível observar o modelo de leitura do professor sendo captado pelo estudante. Segundo Solé (1998), ao ler junto com os alunos, o professor oferece a eles um modelo de leitura, o que pode possibilita que progressivamente eles vão também assumindo a sua responsabilidade no processo de leitura. Mais adiante, esse mesmo estudante ainda reconhece os benefícios dessa atividade, declarando que: "[...] As atividades me ajudaram muito a desempenhar, mas o que falta a interpretação de texto e tudo mais".

A esse respeito, os Parâmetros Curriculares Nacionais de Língua Portuguesa (PCN), na década de 1990, já preconizavam a leitura feita em voz alta pelo professor, afirmando que essa prática:

\footnotetext{
${ }^{3}$ A escrita original dos estudantes foi conservada.
} 
[...] possibilita ao aluno o acesso a textos longos (e às vezes difíceis) que, por sua qualidade e beleza, podem vir a encantá-lo, mas que, talvez, sozinho não o fizesse. A leitura em voz alta feita pelo professor não é prática comum na escola. E, quanto mais avançam as séries, mais incomum se torna, o que não deveria acontecer, pois, muitas vezes, são os alunos maiores que mais precisam de bons modelos de leitores. (BRASIL, PCN, 1998, p. 73)

Do mesmo modo, a leitura compartilhada, além de possibilitar a fruição estética, permite aos estudantes um papel mais ativo e crítico em seu processo de formação, uma vez que nessa atividade eles também assumem o papel de leitor ativo, dando vida ao texto oral, desenvolvendo sua interpretação e entonação, e ainda participam com posicionamentos e indagações sobre o texto. Tais questionamentos foram discutidos e esclarecidos em conjunto com a turma, sendo que alguns alunos não hesitaram em mencionar as várias possibilidades de conhecimentos advindos da leitura literária, citando, por exemplo, que a leitura favorece a ampliação do léxico. Sobre isso, um estudante escreveu: "A leitura compartilhada foi legal, e deu para mim entender as palavras que eu estava com dúvida". Do mesmo modo, ficou perceptível na análise dos textos que a leitura compartilhada possibilitou a eles variadas formas de conhecimento, sobretudo, no âmbito das práticas de linguagem de leitura e de oralidade.

A partir do exemplo oferecido pela professora em termos de ritmo e entonação durante a leitura em voz alta, vários estudantes, ao realizarem essa leitura para os colegas, procuraram, igualmente, fazê-la com propriedade. Da mesma maneira, as discussões ocorridas diariamente acerca da trama durante a leitura de cada capítulo possibilitaram o desenvolvimento de estratégias de compreensão e interpretação por parte dos alunos. Vale citar quanto a isso o depoimento de uma aluna que, embora tenha declarado não gostar de ler, apreciou o modo como a professora conduziu a leitura em voz alta: "A leitura teve partes chatas e legais, as chatas foi as partes que tivemos que ler, as legais as partes que a professora leu como as personagens falavam."

Todavia, conforme o que foi sinalizado pelos PCN na década de 1990, a leitura em voz alta, apesar de seus efeitos positivos no processo de formação de leitores, ainda não é uma atividade comum nos ambientes escolares e o mesmo se aplica às atividades de leitura compartilhada. Neste ponto, destaca-se a importância do papel do(a) professor(a) e das equipes pedagógicas das escolas em dar a devida atenção ao texto literário em sala de aula. Como já discutido ao longo deste texto, embora na esfera do currículo oficial seja aconselhado que os professores deem à literatura o tratamento que ela merece, conforme evidenciam os dados da Retratos da Leitura no Brasil, o trabalho com a educação literária em sala de aula ainda tem se mostrado muito incipiente. 
O número reduzido de livros lidos filiados à literatura, assinalados pelos respondentes da Retratos da Leitura no Brasil, pode ser um sinal da desvalorização da leitura literária na organização do currículo. Tal aspecto também fica evidente na relação de animosidade que os alunos demonstram face ao texto literário, como apontam Saraiva e Mügge (2006), má disposição, também inicialmente presente nas produções dos estudantes do $7^{\circ}$ ano. A título de ilustração, um aluno, em sua primeira produção, momento em que escreveu sobre as razões que o impediram de ler o livro, relatou:

Eu achei o livro Bisa Bia, Bisa Bel chato porque eu não entendi muito bem o livro, na verdade eu não terminei de ler porque eu achei ele muito chato.

Porém, em sua segunda produção, após a leitura compartilhada, escreve:

[...] eu achei bom a professora ler na frente de todos os alunos da sala e explicar. Depois que ela [a Professora] leu eu gostei do livro.

Um outro estudante, em sua primeira produção, revelou:

Eu começei a ler o livro Bisa Bia Bisa Bel, li só o começo e não gostei ai parei de ler porque achei chato e não tive mais a vontade de ler esse livro [...] eu achava que o texto poderia ser mais engraçado.”. Em sua segunda produção, porém, escreveu: “ $A$ professora $V$, o estagiario $J$, e os alunos $K$ e G leram o livro em voz alta, ai começei a entender um pouco [...].

Na primeira produção de uma outra estudante, podemos observar:

[...] li o livro Bisa Bia, Bisa Bel pela metade por causa que depois que Bisa Bel viu o retrato de sua avó que Bisa Bel pensou que era boneca ficou chato eu não gostei.

Essa mesma aluna, após a leitura compartilhada, relatou:

Depois que a professora leu na sala e me ajudou a compreender melhor [...] depois que a professora leu eu gostei bastante.

Nessas declarações, é possível observar o estranhamento inicial dos estudantes diante da complexidade e da especificidade do texto literário, estranhamento, porém, que foi substituído por um sentimento positivo após a leitura compartilhada da obra. Tal aspecto ficou bastante evidente nas produções dos estudantes, o que comprova as teorias defendidas por Pennac (1995) e Machado (2001) sobre a importância exercida pelo professor(a) leitor(a) no processo de fomentação do gosto pela leitura em sala de aula.

Entendemos que os motivos que afastaram os estudantes da leitura individual estão em pleno diálogo com os dados levantados pela Retratos da Leitura no Brasil. De acordo com os relatos dos estudantes, o fato de não terem gostado ou não terem tido interesse pela história foi a principal razão para não terem realizado a leitura individual. O segundo motivo mais citado foi a falta de gosto pela leitura, seguido pela preguiça de ler, falta de tempo/paciência e preferência por outras atividades como forma de entretenimento, respectivamente. Como exemplos, apresentamos alguns depoimentos, que seguem: 
Eu não li o livro Bisa Bisa Bisa Bel por que [...] meu dia é muito corrido [...] eu tenho que ir treina futebol e depois tenho que ir para a escola e depois quando eu chego da escola eu vou mecher no celular. [...] eu li treis folha só e depois eu fiquei com preguiça de ler. (Estudante 1)

Eu peguei o livro na biblioteca, mas não li por que não gosto de ler o porque também não deu tempo"; estudante 3: “[...] eu peguei [o livro] mais não li por que não tive tempo e interesse"; estudante 4: "Eu não consegui ler o livro não tive tempo estava muito ocupado fazendo outras coisas muitas coisas na cabeça [...] mesmo tendo tempo para ler não consegui ou sinão quando tive tempo tinha preguiça ou não queria. (Estudante 2)

Nos relatos elencados, fica evidente a falta de familiaridade dos estudantes com a leitura, cuja atividade, do ponto de vista deles, parece ser algo secundário, de pouca importância. Um exemplo desse apontamento está no depoimento do Estudante 1, que revelou não haver tido tempo para ler Bisa Bia Bisa Bel porque sua rotina já estava preenchida com outras atividades, tais como treinar futebol, ir à escola e utilizar o celular. Mais adiante, esse mesmo aluno, em seu texto, ainda revelou que não leu o livro por ter preguiça, atitude semelhante à do Estudante 4, que afirmou não ter lido a obra por conta de outros compromissos, e, tendo tempo livre, também não leu, porque tinha preguiça. Por seu turno, o Estudante 2 declarou que chegou a emprestar o livro na biblioteca da escola, mas não o leu pelo fato de não gostar de ler e também por não ter tido tempo. A falta de tempo também foi um empecilho para o Estudante 3 não realizar a leitura, além da falta de interesse.

Esses relatos, como se pode ver, vão ao encontro dos dados obtidos pela pesquisa Retratos da Leitura no Brasil, revelando a não predileção dos jovens pela leitura como forma de entretenimento, alinhada à falta de ânimo diante dessa prática social, discursiva e cultural tão importante e necessária para o desenvolvimento humano. Todavia, ainda que esses estudantes tenham feito certas ressalvas em relação à leitura compartilhada, em geral, essa atividade também foi benéfica para eles, pois na produção textual feita após a leitura compartilhada, também apontaram aspectos positivos da atividade, revelando, portanto, uma mudança de atitude em relação à leitura e seu valor, como ilustrado, também, pelos recortes que seguem:

Eela [a professora] leu o livro na sala de aula eu achei + ou - legal [...] eu entendi um pouco, mais eu não lembro muito da historia [...]" (Estudante 1)

[...] bisa bia bisa bel é um livro legal que tem varias coisas que eu aprendi a professora ensinou muito ela leu para nos e assim fomos terminando de ler [...] da minha sala varias pessoas gostaram do livro principalmente eu. (Estudante 2)

[...] a professora leu para a gente, eu achei o livro legal mas ao mesmo tempo chato; a leitura compartilhada foi legal [...]. (Estudante 3)

Ainda que os estudantes 1 e 3 não tenham apreciado totalmente a narrativa Bisa Bia Bisa Bel, em seus depoimentos fica perceptível que a prática da leitura compartilhada os 
aproximou da obra, tendo aumentado o seu interesse pela leitura em geral, e em particular pela literatura. Em vários outros depoimentos também foi possível observar a mudança de opinião inicial em relação ao livro.

Outro aspecto que ficou evidente nessas produções foi o poder humanizador que advém da literatura como já postulava Candido (1972). Tal aspecto se impôs na medida em que, por meio da leitura compartilhada, a narrativa conseguiu mobilizar os alunos para diferentes aspectos da vida social em que estão inseridos, suscitando relações entre a trama narrada com a vida real, aspecto apreensível sobretudo nas memórias de leitura. Uma estudante, por exemplo, entendeu que o livro valoriza a figura da avó ou bisavó, percebendo, de certo modo, uma das razões que levou Ana Maria Machado a escrever essa narrativa, como ela mesma informa na obra em questão:

Eu gostei do livro, pois ele além de discutir as diferenças, brincadeiras e termos de antigamente. Ele fala sobre o valor de uma avó ou bisavó.

Outro estudante alegou ter achado a história um pouco chata em razão de não aprovar as atitudes de alguns personagens, identificando-se com o sofrimento da protagonista Isabel, o que o levou a escrever:

Eu achei [a história] meio chata porque quando a Bisa Bel leva a foto da avó dela para a escola os amigos dela acham engraçado, e isso é meio chato você levar a foto de sua avó e os outros começarem a dar risada até o amigo dela também deu risada.

Convém reiterar que a prática da leitura compartilhada também pode encontrar percalços. Na esfera dessas dificuldades, destaca-se a falta de participação e interesse de alguns estudantes que, muitas vezes, distraem-se com qualquer coisa ou mantêm conversas paralelas durante a atividade. Conforme já foi mencionado, quatro estudantes alegaram não ter prestado atenção na atividade, como mostram estes três exemplos que seguem:

Bem eu não entendi muito bem pois eu não li o livro e não aprestei atenção na leitura compartilhada.

Muitas vezes eu conversava e não prestava atenção.

E eu não consegui muito [entender] o texto, pois os alunos não ficavam quietos.

Em contrapartida, a autoavaliação feita pelos alunos também foi importante, uma vez que assumiram a responsabilidade por não ter prestado atenção na atividade. Segundo Solé (1998), aquele que assume a responsabilidade de organizador da atividade - às vezes professor(a), às vezes estudante - tem a incumbência de envolver os demais. No entanto, não podemos negar que capturar a atenção de adolescentes não é tarefa tão fácil, posto que facilmente se distraem com elementos externos à atividade. $\mathrm{O}$ fato de o estudante não gostar da temática ou do gênero do livro selecionado para a leitura compartilhada já pode ser uma razão para distração, como ilustrado no seguinte relato: "Eu não gostei não achei muito o meu tipo". 
Importante lembrar, então, que na leitura compartilhada professores e alunos devem dividir responsabilidades para o sucesso dessa prática.

Assim, mesmo que alguns alunos não tenham aproveitado os benefícios da leitura compartilhada, fica evidente a sua importância como forma de atuar no processo de formação leitora dos estudantes. Além de terem tido acesso a uma narrativa de boa qualidade literária, ampliaram o vocabulário, desenvolveram a leitura expressiva, o pensamento crítico, a escrita e ainda foram atingidos pela função humanizadora da literatura, uma vez que foram tocados pela história do livro, articulando-a a suas vidas e à realidade, o que certamente possibilitou, em alguma medida, a leitura de si próprio, do outro e do mundo.

\section{Considerações Finais}

A análise dos depoimentos dos alunos, sobretudo dos que não leram Bisa Bia, Bisa Bel sozinhos, evidencia que a leitura compartilhada pode ser uma importante estratégia para inserir alunos não seduzidos pela leitura no universo dessa prática. A atividade pode ser feita em sala de aula desde as séries iniciais e de forma contínua. Quando o(a) professor(a) lê com os estudantes, oferece um exemplo de leitura, aproxima o estudante do universo dos livros ficcionais, da dramaturgia e da poesia, podendo criar condições para que essa prática se torne um hábito na vida dos estudantes. A análise dos textos também mostrou que as obras trabalhadas em sala de aula devem, sim, levar aos estudantes temas novos, que os desafiem, tirando-os de suas zonas de conforto. Todavia, trabalhar com obras cujos temas e gêneros estão mais próximos dos horizontes de expectativas do leitor em formação, igualmente pode ser de grande valia, visto que pode abrir caminhos para a leitura de textos mais complexos. Nesse processo, a mediação do(a) docente se torna crucial. Assim, a boa recepção da obra após a leitura compartilhada, bem como a aprovação dessa estratégia metodológica por parte dos alunos, reiteram a importância e a necessidade de os professores lerem com e para os alunos em sala de aula, prática que pode fomentar não apenas o crescimento intelectual, mas também o desenvolvimento humano em vários sentidos tal como propõe a LDBEN/1996. Cumprindo o papel de mediador de aprendizagem, nessa prática, o(a) professor(a) aproxima os discentes da leitura literária de boa qualidade, podendo mobilizar variadas formas de conhecimento e, sobretudo, ensinando-os a viver, na condição de seres em formação. 


\section{Referências:}

AGUIAR, Vera Teixeira de. \& BORDINI, Maria da Glória. Literatura: a formação do leitor: alternativas metodológicas. 2. Ed. Porto Alegre: Mercado Aberto, 1993.

ANDRADE, Luiza. A leitura feita pelo professor tem que ser constante na alfabetização. 2009. Disponível em: <https://novaescola.org.br/conteudo/2502/a-leitura-feita-pelo-professor-temque-ser-constante-na-alfabetizacao>. Acesso em: 29 ago. 2018.

BORDINI, Maria da G.; AGUIAR, Vera T. Literatura: a formação do leitor. Porto Alegre: Mercado Aberto, 1988.

BRASIL Ministério da Educação. Secretaria da Educação Básica. Base Nacional Comum Curricular. Brasília, DF, 2016. (Disponível em: < http://basenacionalcomum.mec.gov.br>. Acesso em: 20/02/2020. (Versão de 472 páginas).

BRASIL. Lei de Diretrizes e Bases da Educação Nacional. Lei número 9394, 20 de dezembro de 1996.

BRASIL. Secretaria de Educação Fundamental. Parâmetros curriculares nacionais: terceiro e quarto ciclos do ensino fundamental: língua portuguesa. Brasília: MEC/SEF, 1998b. 106 p.

CANDIDO, Antonio. A literatura e a formação do homem. Ciência e cultura (São Paulo). v. 24, n. 9, p. 806-809, set. 1972.

CANDIDO, Antonio. O direito à literatura. In: Vários escritos. 3. ed. rev. e ampl. São Paulo: Duas Cidades, 1995.

CANDIDO, Antonio. Literatura e Sociedade: Estudo de Teoria e História Literária. 12 ed. Revista pelo autor, Rio de Janeiro: Ouro sobre Azul, 2011.

CARVALHO. Neuza Ceciliato de. A emancipação do sujeito infantil pela discursividade do delírio em Bisa Bia, Bisa Bel. In: ANTUNES, Benedito; PEREIRA Maria Teresa Gonçalves (Org.). Trança de Histórias: a criação literária de Ana Maria Machado. São Paulo: Ed. UNESP - Assis, SP: ANEP, 2004.

CECCANTINI, João Luís. Mentira que parece verdade: os jovens não leem e não gostam de ler. In. Retratos da leitura no Brasil 4. Organização de Zoara Failla. Rio de Janeiro: Sextante, 2016, p. 83 - 98.

CEREJA, William Roberto. Ensino de literatura: uma proposta dialógica para o trabalho com a literatura. São Paulo: Atual, 2005.

COSSON, Rildo. Letramento literário: teoria e prática. São Paulo: Contexto, 2006.

FAILLA, Z. (Org.). Retratos da leitura no Brasil 4. Rio de Janeiro: Sextante, 2016. Disponível em: http://prolivro.org.br/home/images/2016/RetratosDaLeitura2016_LIVRO_EM_PDF_ FINAL_COM_CAPA.pdf. Acessado em 02/02/2018.

FREIRE, Paulo. A importância do ato de ler: em três artigos que se completam. 26. ed. São Paulo; Cortez: Autores Associados, 1991. (Coleção polêmicas do nosso tempo, v.4)

INSTITUTO PAULO MONTENEGRO. INAF Brasil 2018: resultados preliminares. [S.1.]: IPM, 2018.

JOUVE, Vicent. A leitura. Trad. Brigitte Hervot. São Paulo: Editora UNESP, 2002.

LAJOLO, Marisa. Carta aos leitores. In. MACHADO, Ana Maria. Bisa Bia, Bisa Bel. Ilustrações de Regina Yolanda. Coordenação editorial de Maristela Petrilli de Almeida Leite e Pascoal Soto, v. 3, 2001. 
LERNER, Delia. Ler e escrever na escola: o real, o possível e o necessário. Tradução de Ernani Rosa. Porto Alegre: Artmed, 2002.

MACHADO, Ana Maria. Bisa. Bisa Bia, Bisa Bel. São Paulo: Moderna, 2001

MACHADO, Ana Maria. Texturas: sobre leitura e escritos. Rio de Janeiro: Nova Fronteira, 2001.

MORTATTI, Mario do Rosário Longo. Literatura (a boa): mantenha sempre ao alcance das crianças. Criar - Revista de Educação Infantil. Ano 3, nº 18, nov/dez, 2007.

PENNAC, Daniel. Como um romance. Trad. Leny Werneck. 2. ed. Rio de Janeiro: Rocco, 1995.

PRÓ-LIVRO. Retratos da leitura no Brasil. 4.ed. março/2016. Disponível em: http://prolivro.org.br/home/images/2016/Pesquisa_Retratos_da_Leitura_no_Brasil_-2015.pdf. Acessado em 02/02/2018.

ROCCO, Maria Thereza Fraga. Literatura/Ensino: uma problemática na escola. Prefácio de Antonio Candido. São Paulo: Ática, 1981. (Ensaios, 77)

SARAIVA, Juracy Assmann; MÜGGE, Ernani. Literatura na escola: propostas para o ensino fundamental. Artmed Editora, 2009.

SOLÉ, Isabel. Estratégias de Leitura. Tradução de Cláudia Schilling. 6.ed. Porto Alegre: Artmed, 1998.

ZILBERMAN, Regina. A Literatura Infantil na Escola. 11ª . ed. São Paulo: Global, 2003.

Recebido em 19 de julho de 2020. Aceito em 20 de janeiro de 2021. 